\title{
TLR9 and BAFF: Their expression in patients with IgA nephropathy
}

\author{
WEIWEI LI ${ }^{1,2^{*}}$, XIAOFEI PENG ${ }^{1 *}$, YUYUAN LIU ${ }^{1}$, HONG LIU $^{1}$, FUYOU LIU ${ }^{1}$, LIYU HE ${ }^{1}$, YANG LIU ${ }^{1}$, \\ FAN ZHANG $^{1}$, CHUNYAN GUO $^{1}$, GUOCHUN CHEN ${ }^{1}$, LEI ZHANG ${ }^{1}$, ZHENG DONG $^{1}$ and YOUMING PENG ${ }^{1}$ \\ ${ }^{1}$ Department of Nephrology, Renal Research Institute, Hunan Key Laboratory of Kidney Disease and Blood Purification, \\ Second Xiangya Hospital, Central South University, Changsha, Hunan 410011; ${ }^{2}$ Department of Nephrology, \\ People's Hospital Binzhou City, Binzhou, Shandong 256610, P.R. China
}

Received July 19, 2013; Accepted February 21, 2014

DOI: $10.3892 / \mathrm{mmr} .2014 .2359$

\begin{abstract}
Since it was first described in 1968, immunoglobulin ( $\operatorname{Ig}) \mathrm{A}$ nephropathy (IgAN) has become the most commonly diagnosed form of primary glomerular disease worldwide. A number of reports have shown that toll-like receptor 9 (TLR9) and B-cell activating factor (BAFF) may be associated with IgAN; however, sufficient evidence has not yet to be delivered. In the present study, serum levels of BAFF as well as TLR9 mRNA and protein levels in peripheral blood mononuclear cells (PBMCs) were assessed. Expression of TLR9 mRNA in PBMCs was examined by quantitative polymerase chain reaction and the TLR9 protein was determined by western blot analysis. The levels of serum BAFF and IgA1 were determined by specific ELISA. Serum levels of BAFF and IgA1 as well as levels of TLR9 mRNA and protein in PMBCs were significantly higher in patients with IgAN compared with patients with minimal glomerular abnormalities $(\mathrm{P}<0.05, \mathrm{P}<0.01, \mathrm{P}<0.01$ and $\mathrm{P}<0.01$, respectively) and normal controls $(\mathrm{P}<0.01, \mathrm{P}<0.01, \mathrm{P}<0.05$ and $\mathrm{P}<0.01$, respectively). A correlation and regression analysis was performed to determine the pathogenesis of $\operatorname{Ig} \mathrm{AN}$. In patients with $\operatorname{Ig} \mathrm{AN}$, serum levels of BAFF were positively correlated with IgA1 levels (rp, 0.515; $\mathrm{P}<0.01)$ and mesangial IgA deposition density (rp, 0.746; $\mathrm{P}<0.01$ ). Expression levels of TLR9 protein in PBMCs of IgAN patients were positively correlated with levels of serum BAFF (rp, 0.444; $\mathrm{P}<0.05$ ) and IgA1 (rp, 0.633; P<0.01). These results suggested that overexpression of TLR9 mRNA and protein in PBMCs and
\end{abstract}

Correspondence to: Professor Hong Liu, Department of Nephrology, Renal Research Institute, Hunan Key Laboratory of Kidney Disease and Blood Purification, Second Xiangya Hospital, Central South University, 139 Renmin Road, Changsha, Hunan 410011, P.R. China

E-mail: liuh0618@163.com

*Contributed equally

Key words: IgA nephropathy, TLR9, BAFF, IgA1 elevated levels of serum BAFF may be associated with overexpression of serum IgA1, and, furthermore, may have a role in the development of $\operatorname{Ig} \mathrm{AN}$.

\section{Introduction}

Since it was first described in 1968, IgA nephropathy (IgAN) has become the most commonly diagnosed form of primary glomerular disease worldwide (1) and remains a significant cause of end stage renal disease (2-4). IgAN is characterized by an overrepresentation of $\operatorname{IgA} 1$ molecules in the serum and mesangial deposition of IgA immune complexes, accompanied by mesangial proliferative glomerulonephritis. Clinically, the main manifestations of IgAN are hematuria and/or proteinuria which frequently emerge or worsen following upper respiratory tract infection. Mesangial deposition of IgA, particularly polymeric IgA1 (pIgA1), was hypothesized to be an initiating event in the pathogenesis of $\operatorname{Ig} \mathrm{AN}$ (5). However, the mechanism of $\operatorname{Ig} \mathrm{A} 1$ production remains to be determined.

Activation of toll-like receptor 9 (TLR9) in the mucosal tissue, including tonsils, stimulated by upper respiratory infection or bacteria, which contain CPG-DNA, have an important role in the occurrence and progression of $\operatorname{IgAN}(6)$. B-cell activating factor (BAFF) is an important immune regulatory factor which is involved in B cell proliferation, differentiation and secretion of IgA1 immunoglobulin. A previous study found that tonsil mononuclear cells (TMCs) of IgAN patients stimulated by IFN- $\gamma$ in vitro induced increased BAFF secretion and proliferation of TMCs (7). However, research on the expression of BAFF and TLR9 in blood circulation and their association has rarely been reported. In the present study, the levels of serum BAFF as well as levels of TLR9 mRNA and protein in PBMCs were evaluated, and correlation and regression analyses were performed in order to investigate the pathogenesis of IgAN.

\section{Materials and methods}

Subjects. IgAN patient group: 30 patients were admitted to the Second Xiangya Hospital (Changsha, China) between August 2011 and February 2012 for a renal biopsy check. IgAN patients 
(14 men and 16 women; age range, 13-63 years; mean age, $33.63 \pm 14.04$ years; course of disease, one month to six years) were identified by immunohistopathological examination of renal biopsy specimens. IgAN was diagnosed on the basis of mesangial cell proliferation and mesangial matrix expansion under light microscopy and detection of predominantly granular mesangial IgA deposits by immunofluorescence. Renal frozen sections were cut into $5-\mu \mathrm{m}$ thick sections and then incubated with rabbit anti-human antibody (Dako, Denmark, Copenhagen) for direct immunofluorescence examination. The range of IgA fluorescence intensity was between $1+$ and $5+$. Systemic lupus erythematosus, Henoch-Schnlein purpura and hepatic diseases were excluded by clinical history, physical examination and negative laboratory test results. All IgAN patients exhibited hematuria and normal renal function, while 11 exhibited proteinueria. Prior to biopsy, patients that were selected were not undergoing drug therapy which influences PBMCs, including corticosteroids, immunosuppressants and antibiotics.

Minimal glomerular abnormalities (MGA) group: 30 patients (14 men and 16 women; age range, 23-55 years; mean age, $36.73 \pm 13.99$ years) were admitted to the Second Xiangya Hospital (Changsha, China) for renal diseases between August 2011 and February 2012. Glomerular minor lesion was diagnosed on the basis of light microscopy and immunofluorescence studies, and patients with IgA deposits were excluded. All patients had normal renal function.

Normal control group: 30 individuals (14 men and 16 women; age range, 15-60 years; mean age, $33.87 \pm 10.47$ years) were selected from individuals admitted to the Health Examination Center of the Second Xiangya Hospital (Changsha, China) between November 2011 and February 2012. Based on laboratory tests and clinical manifestations, viral hepatitis, renal disease, diabetes, heart disease and other diseases were excluded and all individuals did not present with respiratory, gastrointestinal tract or other mucosal infections.

The study was performed in accordance with 'Ethical Principles for Medical Research Involving Human Subjects' (World Medical Association Declaration of Helsinki, 2004) and approved by the Ethics Review Committee of the Second Xiangya Hospital of Central South University and the Hunan Government Medical Research Council. Oral informed consent was obtained from all the subjects.

Specimen collection. Morning fasting blood of all subjects was collected, serum was isolated within $2 \mathrm{~h}$ and preserved for IgA1 and BAFF evaluation. Mononuclear cells were isolated by density gradient centrifugation using Lymphocyte Separation Medium (Sigma-Aldrich, St. Louis, MO, USA). The cells were washed twice with a minimal essential medium supplemented with $7.5 \mathrm{~mol} / 1$ hydroxyethyl piperazineethanesulfonic acid and 2\% heat-inactivated fetal calf serum, and TLR 9 mRNA and protein were evaluated by quantitative polymerase chain reaction (qPCR) and western blot analysis, respectively. The first morning urine of $\operatorname{IgAN}$ patients was collected for urine sediment test within $2 \mathrm{~h}$. According to the results of the urinary sediment artificial red blood cell (RBC) count, the degree of hematuria was divided into four ranks: $<8$ (0), 8-50 (1), 50-100 (2) and >100,000 (3).
Determination of serum IgAl and BAFF. Serum IgA1 and BAFF levels were determined by specific ELISA using horseradish peroxidase (HRP)-labeled goat anti-human IgA1 and BAFF as the detector antibody. A commercial ELISA kit (R\&D Systems, Minneapolis, MN, USA) was used to measure BAFF and IgA1 and the amount of BAFF and IgA1 was measured by spectrophotometry at $450 \mathrm{~nm}$ using a microplate reader (Molecular Devices, Silicon Valley, CA, USA).

qPCR analysis for TLR9 $m R N A$ expression. Total RNA was extracted from freshly isolated cells using TRIzol ${ }^{\circledR}$ reagent (Invitrogen Life Technologies, Carlsbad, CA, USA), and was reverse-transcribed into cDNAs with SuperScript ${ }^{\mathrm{TM}}$ II Reverse Transcriptase. PCR amplification of TLR9 was performed using two primers: TLR9 forward, (5'-CTCACCCACCTGTCACTCAAG) and reverse, (5'-AGTTTGACGATGCGGTTGTAG), which generated a specific $104 \mathrm{bp}$ PCR product following 30 cycles of PCR reaction $\left(30 \mathrm{sec}\right.$ at $95^{\circ} \mathrm{C}, 30 \mathrm{sec}$ at $56^{\circ} \mathrm{C}$, and $60 \mathrm{sec}$ at $72^{\circ} \mathrm{C}$ ). $\beta$-actin was amplified as a control.

Western blot analysis of TLR9 protein expression. Cells were lysed with Nonidet P-40 (NP-40) lysis buffer (20 mM Tris- $\mathrm{HCl}$ $\mathrm{pH} 7.5,150 \mathrm{mM} \mathrm{NaCl}$, and $1 \% \mathrm{NP}-40$ ) in the presence of protease inhibitors at $4^{\circ} \mathrm{C}$. Following incubation for $30 \mathrm{~min}$, the lysates were centrifuged at $4^{\circ} \mathrm{C}$ for $10 \mathrm{~min}$ at $10,000 \mathrm{x} \mathrm{g}$. The protein concentrations of the lysates were measured using a BCA method (BCA Protein Assay kit; Bio-Rad, Hercules, CA, USA). Soluble lysates were boiled for $5 \mathrm{~min}$ with $2 \mathrm{X}$ SDS sample buffer. Samples (40 mg per lane) from the total protein fraction were loaded and separated by SDS-PAGE. Protein was transferred to polyvinylidene difluoride membranes (Pharmacia Corporation, Peapack, NJ, USA) and probed with primary antibodies against human TLR9 (goat polyclonal antibody; R\&D Systems). The primary antibodies that bound to the target proteins were detected using HRP-conjugated anti-goat immunoglobulin G (Promega Corporation, Madison, WI, USA). The antibodies were visualized with enhanced chemiluminescent detection (Pierce Biotechnology Inc., Rockford, IL, USA).

Statistical analysis. SPSS version 16.0 (SPSS Inc., Chicago, IL, USA) for Windows was used for data analysis. Continuous variables were expressed as mean \pm standard deviation. Comparisons were based on the $\chi^{2}$ test for categorical data, and analysis of variance for quantitative data and data at different time-points were performed. Correlations between the parameters were analyzed by the Spearman's rank correlation analysis. $\mathrm{P}<0.05$ was considered to indicate a statistically significant difference.

\section{Results}

Serum levels of BAFF are increased in IgAN. The serum BAFF levels of all subjects in the different groups are shown in Fig. 1. Serum levels of BAFF in the IgAN, MGA and normal control groups were $3.41 \pm 2.13,2.05 \pm 1.018$, and $1.86 \pm 0.99 \mathrm{ng} / \mathrm{ml}$, respectively. The serum levels of BAFF in the IgAN group were significantly increased compared with 


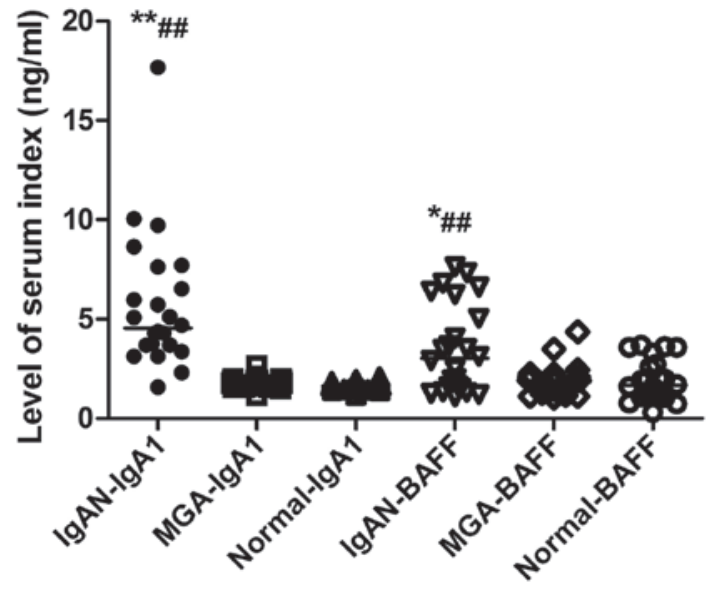

Figure 1. Levels of serum BAFF and IgA1 in all groups; the median levels are marked with horizontal line. ${ }^{*} \mathrm{P}<0.05$, vs. MGA patients; ${ }^{* *} \mathrm{P}<0.01$, vs. MGA patients; ${ }^{\# \prime} \mathrm{P}<0.01$, vs. normal controls. MGA, minimal glomerular abnormalities; Ig, immunoglobulin; IgAN, IgA nephropathy; BAFF, B cell activating factor.

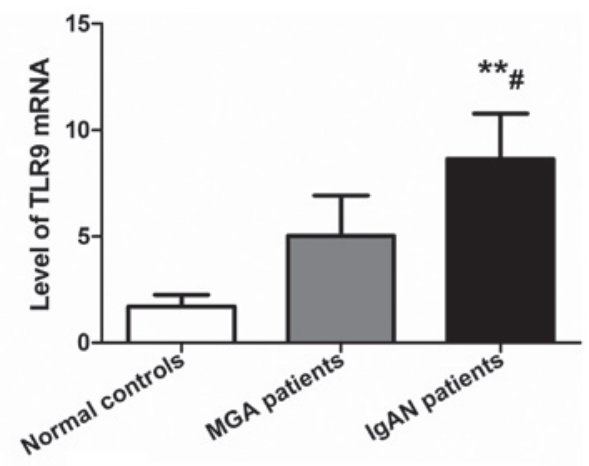

Figure 2. Comparison of TLR9 mRNA expression in peripheral blood mononuclear cells between groups. ${ }^{\#} \mathrm{P}<0.05$, vs. MGA patients; ${ }^{* *} \mathrm{P}<0.01$, vs. normal controls. MGA, minimal glomerular abnormalities; TLR9, toll-like receptor 9; IgAN, immunoglobulin A nephropathy.

the MGA $(\mathrm{P}<0.05)$ and normal control $(\mathrm{P}<0.01)$ groups, while there was no difference between the MGA and normal control groups $(\mathrm{P}>0.05)$.

Serum levels of IgAl are increased in IgAN. The serum IgA1 levels of all subjects in the different groups are presented in Fig. 1. Serum levels of $\operatorname{IgA} 1$ in the $\operatorname{IgAN}$, MGA and normal control groups were $6.21 \pm 3.89,1.78 \pm 0.26$, and $1.66 \pm 0.23 \mathrm{ng} / \mathrm{ml}$, respectively. Serum levels of $\operatorname{IgA} 1$ in the IgAN group were significantly increased compared with the MGA $(\mathrm{P}<0.01)$ and normal control $(\mathrm{P}<0.01)$ groups, while there was no difference between the MGA and normal control groups $(\mathrm{P}>0.05)$.

TLR9 mRNA levels in PBMCs are increased in IgAN. Levels of TLR9 mRNA in PBMCs in the IgAN, MGA and normal control groups were $8.65 \pm 2.12,5.03 \pm 1.89$, and $1.71 \pm 0.54$, respectively. qPCR data were analyzed by the $2^{-\Delta \Delta C t}$ method and are shown in Fig. 2. TLR9 mRNA levels in PBMCs in IgAN patients were significantly higher compared with the MGA $(\mathrm{P}<0.05)$ and normal control $(\mathrm{P}<0.01)$ groups, while

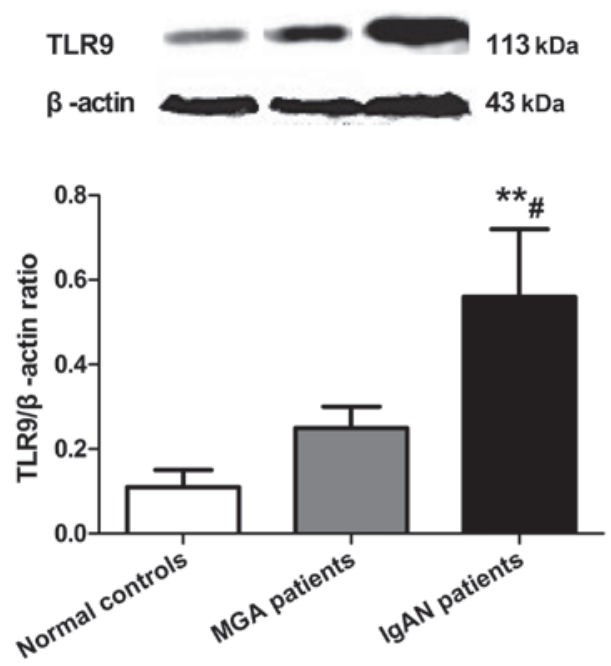

Figure 3. Comparison of TLR9 protein expression in peripheral blood mononuclear cells between groups. ${ }^{\#} \mathrm{P}<0.05$, vs. MGA patients; ${ }^{* *} \mathrm{P}<0.01$, vs. normal controls. MGA, minimal glomerular abnormalities; TLR9, toll-like receptor 9; IgAN, immunoglobulin A nephropathy.

there was no significant difference between the MGA and normal control groups $(\mathrm{P}>0.05)$.

TLR9 protein levels in PBMCs are increased in IgAN. Expression levels of TLR9 protein in PBMCs in the IgAN, MGA and normal control groups were $0.56 \pm 0.16,0.25 \pm 0.05$, and $0.11 \pm 0.04$, respectively (Fig. 3). TLR9 protein expression in PBMCs in the IgAN group was significantly higher compared with the MGA $(\mathrm{P}<0.05)$ and normal control $(\mathrm{P}<0.01)$ groups, while there was no difference between the MGA and normal control groups $(\mathrm{P}>0.05)$.

Correlation analysis. By correlation and regression analysis, it was observed that serum levels of BAFF were positively correlated with serum levels of $\operatorname{IgA} 1$ (rp, 0.515, P<0.01; Fig. 4A) and mesangial IgA deposition density ( $\mathrm{P}<0.01$, rp, 0.746; Fig. 4B), while there was no correlation between rank of urinary $\mathrm{RBC}$ count and serum levels of BAFF (Fig. 4C) and IgA1 (Fig. 4D) in $\operatorname{Ig} A N$ patients $(\mathrm{P}<0.05$, respectively).

The correlation and regression analysis suggested that the expression levels of TLR9 protein in PBMCs were positively correlated with serum levels of BAFF (rp, 0.444, $\mathrm{P}<0.05$; Fig. 5A) and $\operatorname{IgA} 1$ (rp, 0.633, $\mathrm{P}<0.01$; Fig. 5B) in the IgAN group.

\section{Discussion}

Polymeric IgA1 (pIgA1) has been suggested to be the initiating event in the pathogenesis of IgAN; however, the mechanism of polymeric $\operatorname{IgA} 1$ formation is obscure (5). Previous studies revealed that the serum and tonsil tissue levels of IgA1 were elevated $(8,9)$ and the number of IgA-producing lymphocytes was increased in the serum of patients with $\operatorname{IgANs}$. In the present study, the serum levels of IgA1 were observed to be significantly higher in patients with $\operatorname{Ig} \mathrm{AN}$ compared with the MGA and normal control groups $(\mathrm{P}<0.01)$, which is consistent with a previous study (9). Clinically, gross hematuria frequently emerges following upper respiratory infections; thus, it is hypothesized that mucosal immunity stimulated by 
A

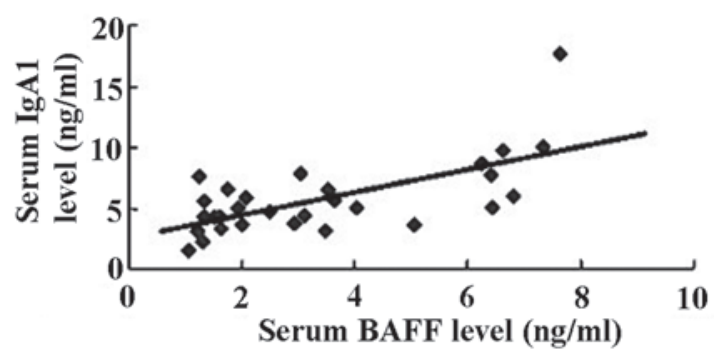

C

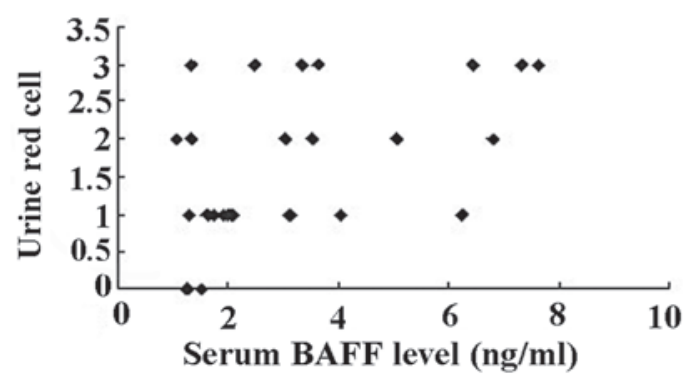

B

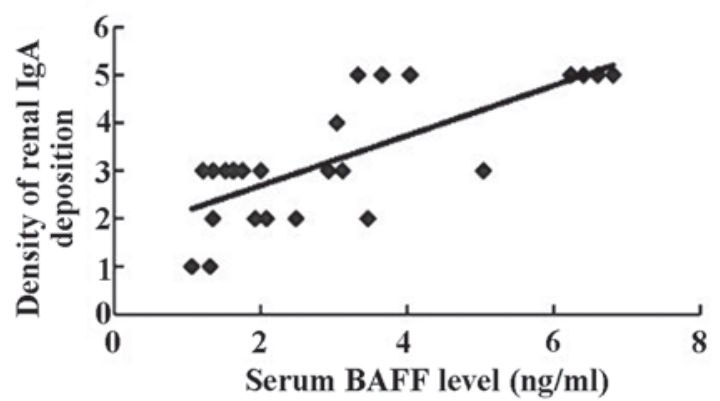

D

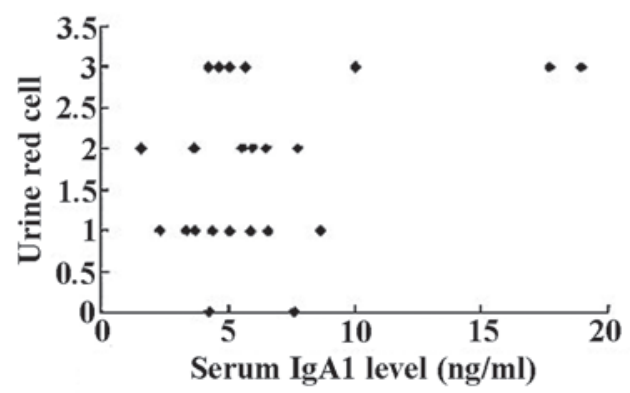

Figure 4. (A) Correlation between levels of serum BAFF and IgA1 in IgAN patients group (rp, 0.515; P<0.01). (B) Correlation between levels of serum BAFF and density of mesangial IgA deposition in IgAN patients group ( $\mathrm{P}<0.01$; rp, 0.746). (C) Correlation between levels of serum BAFF and rank of urinary $\mathrm{RBC}$ count in IgAN patients group (P>0.05; rp, 0.133). (D) Correlation between levels of serum IgA1 and rank of urinary RBC count in IgAN patients group (P>0.05; rp, 0.079). RBC, red blood cell; Ig, immunoglobulin; IgAN, IgA nephropathy; BAFF, B cell activating factor.
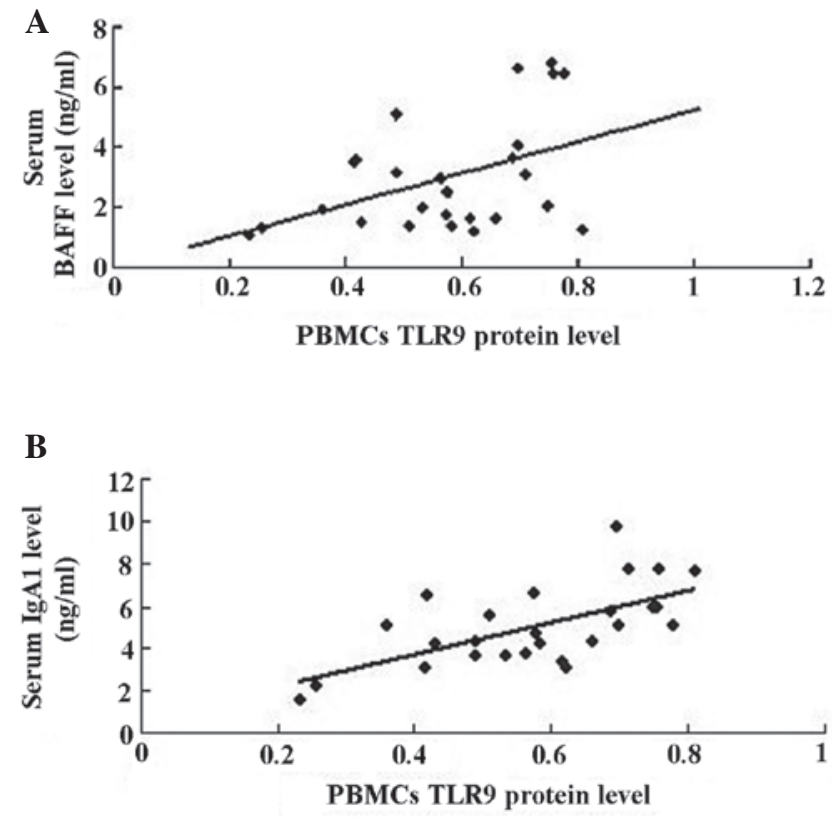

Figure 5. Correlation of TLR9 protein expression in PBMCs and levels of serum indexes. (A) Correlations between TLR9 protein expression in PBMCs and serum BAFF levels in IgAN patients group (rp, 0.444; $\mathrm{P}<0.05$ ). (B) Correlations between TLR9 protein expression levels in PBMCs and serum IgA1 levels in IgAN patients group (rp, 0.633; P<0.01). PBMCs, peripheral blood mononuclear cells; BAFF, B cell activating factor; TLR9, toll-like receptor 9; Ig, immunoglobulin; IgAN, IgA nephropathy.

cytosine-guanine dinucleotide $(\mathrm{CpG})$-DNA is important in the pathogenesis of $\operatorname{IgAN}(7)$. In mouse models, intranasal immunization with $\mathrm{CpG}-\mathrm{DNA}$ induced marked systemic and local IgA responses (10), and clinically presented with increased levels of serum $\operatorname{IgA}$, hematuria, proteinuria and renal $\operatorname{Ig} \mathrm{A}$ deposition intensity (11). In previous studies by our group, the levels of IgA1 in tonsil mononuclear cells stimulated by lipopolysaccharide or hemolytic streptococcus in the IgAN group were significantly increased compared with the unstimulated group (12).

TLR9 is a member of the TLR family (12) and mainly recognizes the $\mathrm{CpG}$ motif in unmethylated bacterial DNA. Oligodeoxynucleotides (ODNs) with CpG (CpG-ODN) are capable of mimicking the immunostimulatory activity of microbial DNA (14). Kajiyama et al (11) observed that three CpG-ODNs, which were inoculated nasally in mice, may result in different manifestations by stimulating TLR9 of B cells and/or dendritic cells. Therefore, a number of researchers hypothesized that the activation of TLR9 in the mucosa may be involved in the pathogenesis of $\operatorname{Ig} \mathrm{AN}(15-17)$. Suzuki et al (6) also demonstrated that activation of the TLR9/myeloid differentiation (MyD)88 pathway by common antigens may have a role in the development of IgAN and affect its severity. In the present study, the levels of TLR9 mRNA and protein in PBMCs of patients with IgAN were higher than those in the MGA and normal control groups, which further validated the role of TLR9 in IgAN.

BAFF is a member of the tumor necrosis factor family, is critical for the maintenance of normal B-cell development and homeostasis (18) and is closely associated with autoimmune diseases $(18,19)$. The BAFF protein is mainly expressed by myeloid lineage cells, including dendritic cells $(20,21)$, and its expression is upregulated by interferon- $\gamma$ and interleukin-10 (22). To date, studies have shown that CpG-ODN may upregulate the expression and secretion of BAFF and the recognized detailed processes are as follows: Only TLR9 or 
B cells have a role in CpG-ODN-promoted myeloid cell secretion of IL-12, IL-18, IFN- $\alpha$. Furthermore, the above cytokines promote NK cells secreting IFN- $\gamma$, which may upregulate the secretion of BAFF. Finally, BAFF promotes proliferation and antibody secretion of $\mathrm{B}$ cells by the interaction between BAFF and the B cell surface receptor (20,23-25). McCarthy et al (24) reported that $\mathrm{BAFF}$-transgenic mice showed an increase in serum $\operatorname{Ig}$ A levels, as well as a deposition of $\operatorname{IgA}$ immune complexes in the renal glomerular mesangium (26). Recently, Xin et al (27) showed that levels of serum BAFF were elevated in patients with $\operatorname{IgAN}$ and were associated with clinical and pathological features of the disease. These observations indicate that BAFF may be involved in the development of IgAN. The present study also revealed that the levels of serum BAFF were significantly higher in the IgAN compared with the MGA and normal control groups $(\mathrm{P}<0.05 ; \mathrm{P}<0.01)$, and a significantly positive correlation between serum BAFF levels and the IgA deposition in density glomeruli $(\mathrm{P}<0.01$; rp, 0.746) was observed, while no correlation between levels of serum IgA1 and the rank of urinary RBC count $(\mathrm{P}>0.05)$ was observed. Therefore, serum BAFF is hypothesized to be closely associated with hyper-production of $\operatorname{Ig} \mathrm{A} 1$, which has a key role in the pathogenesis of $\operatorname{IgAN}$.

Previously, $\alpha$-hemolytic streptococci have been isolated and identified in all patients with IgAN (28). It has been confirmed that the hemolytic streptococcus contains CpG-DNA, which may activate TLR9 in human B cells and plasmacytoid dendritic cells (pDCs) (29). The initial target of CpG-DNA is the plasmacytoid dendritic cells, and it may upgrade the expression of the TLR9 through stimulating pCDs. TLR9 activation of B cells may increase the antigenic response sensitivity, promote B cell differentiation into antibody-secreting plasma cells, and have a role in the adaptive immune response. However, the mechanism of TLR9 in the activation of B cells remains unknown. Fujieda et al (30) showed that the expression levels of IFN- $\gamma$ and $\operatorname{Ig} \mathrm{A}$ in tonsil mononuclear cells were significantly higher in patients with $\operatorname{Ig} \mathrm{AN}$ compared with patients with chronic tonsillitis and it was hypothesized that IFN- $\gamma$ has a role in the pathogenesis of $\operatorname{IgAN}$. Goto et al (7) demonstrated that when stimulated with CpG-ODN, the production of IgA, BAFF and IFN- $\gamma$ in TMCs were significantly increased in patients with IgAN compared with a control group. IgA production may be inhibited by the treatment with anti-BAFF and/or anti-IFN- $\gamma$ antibodies, while treatment with IFN- $\gamma$ significantly increased the expression of BAFF in CD1c cells and TMCs in patients with IgAN compared with those in a control group. Therefore, Goto et al (7) hypothesized that a hyper-immune response to microbial DNA may be present in patients with IgAN and may induce IFN- $\gamma$-mediated upregulation of BAFF, resulting in overexpression of $\operatorname{IgA}$ in patients with $\operatorname{IgAN}$.

Pontarollo et al (29) reported that the ability of CpG-ODN to stimulate IFN- $\gamma$ secretion was entirely abrogated by the depletion of DH59B cells and that B-cell proliferation was significantly reduced. Buchanan et al (31) showed that when purified bovine B cells were co-cultured with $\mathrm{CD}_{14}{ }^{+}$myeloid cells and/or BAFF, there was a significant increase in CpG-specific B-cell proliferation. Furthermore, Buchanan et al (31) found that stimulation with $\mathrm{CpG}$ helper cells in mononuclear cells may secrete a number of cytokines, which may activate antigens on B cells, including TLR9, and may indirectly promote activation of B cells. A previous study (32) also found that stimulation by CpG-ODN bovine peripheral $\mathrm{CD} 21^{+} \mathrm{B}$ cells may express TLR9 and proliferation in mixed cell populations. Based on a number of studies, the present study confirms that stimulation with CpG-ODN myeloid cells may secrete IL-12, IL-8 and IFN, which promotes the secretion of IFN- $\gamma$ by NK cells. IFN- $\gamma$ upgrades BAFF secretion and the excessive secretion of BAFF upregulates $B$ cell activity, including proliferation and differentiation into antibody-secreting cells. Finally, induced abnormal secretion of IgA and renal IgA deposition cause hematuria and proteinuria. In the present study, the expression levels of TLR9 were significantly correlated with the serum levels of BAFF and IgA1 in patients with $\operatorname{Ig} \mathrm{AN}(\mathrm{P}<0.05, \mathrm{P}<0.01$, respectively). Thus, it was hypothesized that in the peripheral blood, TLR9 may increase the expression levels of BAFF, which promotes B lymphocytes to secrete immunoglobulins, particularly IgA1. A previous study also reported that BAFF is a co-stimulator of TLR and B-1 cells (33). From these studies, it is hypothesized that the high immune status induced by microorganism DNA may result in the excessive secretion of BAFF, thus leading to the excessive secretion of $\operatorname{Ig}$ A through the activation of B-1 cells.

In conclusion, TLR9 mRNA and protein levels in PBMCs as well as serum levels of BAFF were significantly increased and may be associated with the overexpression of serum IgA1 in patients with $\operatorname{Ig} \mathrm{AN}$.

\section{Acknowledgements}

This study was supported by grants from the Key Program (no. 81170663) of the National Natural Science Foundation of China and the Program of the Natural Science Foundation of Hunan province (no. 12JJ6094).

\section{References}

1. D'Amico G: The commonest glomerulonephritis in the world: IgA nephropathy. Q J Med 64: 709-727, 1987.

2. Appel GB and Waldman M: The IgA nephropathy treatment dilemma. Kidney Int 69: 1939-1944, 2006.

3. Barratt J and Feehally J: IgA nephropathy. J Am Soc Nephrol 16: 2088-2097, 2005

4. Julian BA and Novak J: IgA nephropathy: an update. Curr Opin Nephrol Hypertens 13: 171-179, 2004.

5. Lai KN: Pathogenesis of IgA nephropathy. Nat Rev Nephrol 8: 275-283, 2012.

6. Suzuki H, Suzuki Y, Narita I, et al: Toll-like receptor 9 affects severity of IgA nephropathy. J Am Soc Nephrol 19: 2384-2395, 2008.

7. Goto T, Bandoh N, Yoshizaki T, et al: Increase in B-cell-activation factor (BAFF) and IFN-gamma productions by tonsillar mononuclear cells stimulated with deoxycytidyl-deoxyguanosine oligodeoxynucleotides (CpG-ODN) in patients with IgA nephropathy. Clin Immunol 126: 260-269, 2008.

8. Suzuki S, Fujieda H, Sunaga H, et al: Immune response of tonsillar lymphocytes to Haemophilus parainfluenzae in patients with $\operatorname{IgA}$ nephropathy. Clin Exp Immunol 119: 328-332, 2000.

9. Fujieda S, Suzuki, H, Sunaga, et al: Induction of IgA against Haemophilus parainfluenzae antigens in tonsillar mononuclear cells from patients with IgA nephropathy. Clin Immunol 95: 235-243, 2000.

10. McCluskie MJ, Weeratna RD and Davis HL: Intranasal immunization of mice with CpG DNA induces strong systemic and mucosal responses that are influenced by other mucosal adjuvants and antigen distribution. Mol Med 6: 867-877, 2000.

11. Kajiyama T, Suzuki Y, Kihara M, et al: Different pathological roles of toll-like receptor 9 on mucosal B cells and dendritic cells in murine IgA nephropathy. Clin Dev Immunol 2011: 819646, 2011. 
12. Liu H, Peng Y, Liu F, Xiao W, Zhang Y and Li W: Expression of IgA class switching gene in tonsillar mononuclear cells in patients with IgA nephropathy. Inflamm Res 60: 869-878, 2011.

13. Krieg AM and Vollmer J: Toll-like receptors 7, 8, and 9: linking innate immunity to autoimmunity. Immunol Rev 220 : $251-269$, 2007.

14. Krieg AM, Yi AK, Matson S, et al: CpG motifs in bacterial DNA trigger direct B-cell activation. Nature 374: 546-549, 1995.

15. Kaisho $\mathrm{T}$ and Akira S: Dendritic-cell function in Toll-like receptor- and MyD88-knockout mice. Trends Immunol 22: 78-83, 2001.

16. Ashkar AA and Rosenthal KL: Toll-like receptor 9, CpG DNA and innate immunity. Curr Mol Med 2: 545-556, 2002.

17. Leadbetter EA, Rifkin IR and Marshak-Rothstein A: Toll-like receptors and activation of autoreactive B cells. Curr Dir Autoimmun 6: 105-122, 2003.

18. Schneider P, MacKay F, Steiner V, et al: BAFF, a novel ligand of the tumor necrosis factor family, stimulates B cell growth. J Exp Med 189: 1747-1756, 1999.

19. Moore PA, Belvedere O, Orr A, et al: BLyS: member of the tumor necrosis factor family and B lymphocyte stimulator. Science 285: 260-263, 1999.

20. Craxton A, Magaletti D, Ryan EJ and Clark EA: Macrophage- and dendritic cell - dependent regulation of human B-cell proliferation requires the TNF family ligand BAFF. Blood 101: 4464-4471, 2003.

21. Scapini P, Nardelli B, Nadali G, Calzetti F, Pizzolo G, Montecucco C and Cassatella MA: A G-CSF-stimulated neutrophils are a prominent source of functional BLyS. J Exp Med 197: 297-302, 2003.

22. Nardelli B, Belvedere O, Roschke V, et al: Synthesis and release of B-lymphocyte stimulator from myeloid cells. Blood 97: 198-204, 2001

23. Bergamin F, Vincent IE, Summerfield A and McCullough KC: Essential role of antigen-presenting cell-derived BAFF for antibody responses. Eur J Immunol 37: 3122-3130, 2007.
24. Jego G, Pascual V, Palucka AK and Banchereau J: Dendritic cells control B cell growth and differentiation. Curr Dir Autoimmun 8: 124-139, 2005

25. Litinskiy MB, Nardelli B, Hilbert DM, He B, Schaffer A, Casali P and Cerutti A: DCs induce CD40-independent immunoglobulin class switching through BLyS and APRIL. Nat Immunol 3: 822-829, 2002

26. McCarthy DD, Chiu S, Gao Y, Summers-deLuca LE and Gommerman JL: BAFF induces a hyper-IgA syndrome in the intestinal lamina propria concomitant with IgA deposition in the kidney independent of LIGHT. Cell Immunol 241: 85-94, 2006.

27. Xin G, Shi W, Xu LX, Su Y, Yan LJ and Li KS: Serum BAFF is elevated in patients with IgA nephropathy and associated with clinical and histopathological features. J Nephrol 26: 683-690, 2012.

28. Huang H, Peng Y, Liu H, Yang X and Liu F: Decreased $\mathrm{CD} 4^{+} \mathrm{CD} 25^{+}$cells and increased dimeric IgA-producing cells in tonsils in IgA nephropathy. J Nephrol 23: 202-209, 2010.

29. Pontarollo RA, Rankin R, Babiuk LA, et al: Monocytes are required for optimum in vitro stimulation of bovine peripheral blood mononuclear cells by non-methylated $\mathrm{CpG}$ motifs. Vet Immunol Immunopathol 84: 43-59, 2002.

30. Fujieda S, Suzuki S, Sunaga H, Yamamoto H, Seki M, Sugimoto $\mathrm{H}$ and Saito H: Production of interferon-gamma by tonsillar mononuclear cells in IgA nephropathy patients. Acta Otolaryngol 120: 649-654, 2000.

31. Buchanan RM, Popowych Y, Arsic N, et al: B-cell activating factor (BAFF) promotes $\mathrm{CpG}$ ODN-induced $\mathrm{B}$ cell activation and proliferation. Cell Immunol 271: 16-28, 2011.

32. Buchanan R, Popowych Y, Dagenais C, et al: Interferon-gamma and B-cell activating factor (BAFF) promote bovine B cell activation independent of TLR9 and T-cell signaling. Vet Immunol Immunopathol 145: 453-463, 2012.

33. $\mathrm{Ng} \mathrm{LG}, \mathrm{Ng} \mathrm{CH}$, Woehl B, et al: BAFF costimulation of Toll-like receptor-activated B-1 cells. Eur J Immunol 36: 1837-1846, 2006. 